\title{
"JOSÉ GREGORIO HERNÁNDEZ" award of the Venezuelan Academy of Medicine at Pembroke College, Oxford University
}

\author{
Francisco Kerdel-Vegas ${ }^{1 *}$, María Isabel Plaza ${ }^{2}$, Pedro Ignacio Carvallo ${ }^{3}$ and Leonardo Lustgarten ${ }^{4}$ \\ ${ }^{1}$ National Academy of Medicine, Caracas, Venezuela \\ ${ }^{2}$ Instituto Dermatologico, Centro Profesional Sta. Paula, Caracas, Venezuela \\ ${ }^{3}$ Head of the Bone Tumors Service, Oncology Services Hospital, Venezuelan Social \\ ${ }^{4}$ Department of Neurosurgery Hospital Clinicas Caracas, Caracas, Venezuela
}

The idea of broadening your medical knowledge by traveling abroad to remote, more advanced countries or to the place of origin of the creative inspired masters, with well-established accomplishments is long standing in the medical profession. Just remember the example of Galen who in the Second Century, upon completing his medical studies in Pergamo, his place of birth, moved to Alexandria in his quest for additional wisdom and experience. This idea has been deeply rooted in our profession that makes no distinction as to geographical, political, ideological, or cultural boundaries for the advancement of our field and the use of knowledge regardless of where that creative and inspiring knowledge develops. This tradition has been present in Venezuela since the early years of our independence when in 1813 Dr. José María Vargas traveled to Edinburgh to further his medical knowledge and when he returned to Venezuela he practiced all what he learned during his educational journey.

Not surprisingly this example was followed by every subsequent generation of physicians, particularly the elite group that chose the academia and research as their ultimate goal. A case in point is that of Dr. José Gregorio Hernández (1864-1919), whose name inspired the fellowship program herein discussed.

Dr. José Gregorio Hernández's memory is alive not only in Venezuela but in neighboring countries as well. He is remembered as a great doctor, scientist, professor, academician, and philanthropist, of profound religious convictions. "He is celebrated for his compassion, generosity, righteousness and service to the poor. His life was a living testimony of holiness to the extent that many Latin Americans consider him a saint, though he has not yet been beatified by the Catholic Church" (Wikipedia).

After the start of the Simón Bolívar Chair at the University of Cambridge in 1967 (with Venezuelan funding and opened to all Latin Americans of intellectual and academic merits) and of the "Andrés Bello Fellowship" at St. Antony's College, Oxford University in 1974 (opened to Venezuelans with academic merits in Social Sciences), these two worldwide famous English Universities that traditionally been rated among the top 10 in the world, the ideal conditions were provided for Venezuelans to complement their educational programs with graduate fellowships at the highest level at different Colleges in both Universities.

The proposal made to these Colleges was based on successful past experiences, setting up a trust fund managed directly by each College and funded by the Venezuelan institution so that the revenues from the trust fund were used to pay for tuition and boarding of the students throughout their studies at Oxford or Cambridge.

Based on the prestige, high esteem, and closeness of one of us to the leaders of these two universities that were highly interested and enthusiastic, the initial approach to implement these fellowships focused on the Academies of Medicine and Sciences (Physical, Mathematics, and Natural Sciences), that were then under the leadership of Dr. Jorge González-Celis and Dr. Miguel Parra-León, respectively.

However, good intentions were not enough. The National Academies operated on lean budgets assigned by the Ministry of Education so to be able to advance these projects the academies had to depend on the generosity of private institutions and patrons that were unacquainted until that moment with this level of philanthropy.

This article refers to fellowships for physicians established by The National Academy of Medicine of Venezuela at Pembroke College, Oxford and at Darwin College, Cambridge. Specifically, the first fellowship program was called "Beca José Gregorio Hernández" as a tribute to the great Venezuelan doctor who is revered around the country for his contributions to experimental medicine and his insightful religiousness.

The fact that the Headmaster of Pembroke College was a famed British physician, Sir George Pickering, who had been Regius Professor of Medicine at Oxford University, and was previously Professor of Medicine at St. Mary's Hospital in London, paved the way to the

Correspondence to: Francisco Kerdel-Vegas, National Academy of Medicine, Caracas, Venezuela; E-mail: francisco.kerdelvegas@gmail.com

Special Issue: Dermatology History in Different Countries

Nooshin Bagherani

Dermatologist at Dr. Nooshin Bagheran's office, Taha Physicians' building, P.O.Box: 6414715878, Khoramshahr, Khuzestan Province, Iran,

Email: nooshinbagherani@yahoo.com

Bruce R. Smoller, M. D.

Chair, Department of Pathology and Laboratory Medicine

Professor, Department of Pathology and Laboratory Medicine

Professor, Department of Dermatology

University of Rochester School of Medicine and Dentistry, USA

E-mail: smollerbrucer@uams.edu

Published: December 20, 2015 
negotiations that preceded the creation of the fellowship program.

Regardless of whether it was providence, destiny, good luck, chance, coincidence, serendipity, or any other name, the fact is that exceptional circumstances helped to bond the fellowship sponsor the National Academy of Medicine, under the leadership of Dr. Jorge González-Celis with the institution that eventually granted the funds, with the "Fundación Premio José Gregorio Hernández" led by Cardinal José Humberto Quintero. Both of them were outstanding Venezuelans, highly representative of ethical and intellectual values, who rose to the top of their respective professions in the same generation, with a significant academic background developed abroad (González-Celis graduated as a physician at the Sorbonne, Paris, while Monsignor Quintero received his theology degree in Rome) and therefore both lived through this type of experience not just to expand and improve their knowledge, but to teach us to become genuine citizens after living for several years in countries with an ancient culture and civilization.

The opportunity emerged some time ago when Cardinal Quintero visited my office (FKV) and asked for my opinion about the best use in medicine of some "surplus" funds of the Fundación Premio José Gregorio Hernández. People were so devoted to the famous physician in our country, that the funds collected far exceeded the statutory needs of the foundation which was set up to promote a prize for research in the medical field. As expected, I used the opportunity to recommend using those surplus funds to create the fellowship program. I immediately reported this to Dr. González-Celis, who very diligently, enthusiastically and diplomatically, took upon himself the task of completing the formalities that led to the donation of the necessary funds required for establishing the fellowship at Oxford.

Consequently, we have two institutions directly involved in creating this fellowship: the National Academy of Medicine of Venezuela, donor of the funds, and Pembroke College, Oxford University, recipient of the funds where the fellowship was established. In this way, the Venezuelan graduate medical student could be admitted to the specialized medical studies at Oxford University, based on the analysis of individual needs and the merits of each selected candidate.

The National Academy of Venezuela is the official, scientific and consultation institution that represents medical sciences in the country, as established under the law. Founded in 1904, the Academy includes as part of its activities since 1974, the selection of physicians that will benefit from the fellowships at Oxford and Cambridge.

\section{Dr. Marisabel Plaza's experience during her training in dermatology in Oxford}

In 1978 I was selected by the National Academy of Medicine of Venezuela as the second recipient of the "José Gregorio Hernández" fellowship granted by the Academy of Sciences with the funds contributed by the José Gregorio Hernández Award Foundation, to pursue a two year graduate program at Oxford University, specifically at Pembroke College. Until that time, Pembroke College was exclusively for male students and I had the privilege and the challenge to be the first postgraduate woman student accepted as a member in the history of Pembroke College.

My training in dermatology began in 1978, based on hospital and research work, under the supervision of Dr.Terence Ryan and Dr. Rodney Dawber, both heads of the Dermatology Department.

The first year my daily work took place at two hospitals, Slade Hospital and Radcliffe Infirmary and then at John Radcliffe Hospital, since the outpatient clinic was transferred to this latter hospital.

Most of my dermatological training and education took place at Slade Hospital: 1) Admission and control of hospitalized patients; 2) Healthcare and consultation at the Industrial, Psoriasis, Dermatological surgery, and Cryosurgery clinics; 3 ) Internships at the Tropical Medicine unit; and 4) attendance to weekly histopathology sessions.

The Radcliffe Infirmary and later John Radcliffe Hospital only offered outpatient services and control of patients undergoing treatment or discharged from Slade Hospital.

In addition to the hospital activity we were exposed to: 1) monthly combined dermatology, oncology, and reconstructive surgery clinics, with presentation and discussion of clinical cases; and 2) attendance to monthly meetings of the British Society of Dermatology in London.

During my training I was responsible for controlling and supervising the PUVA Therapy and Cryosurgery unit, and I had the honor of presenting the paper: "Bowen's disease Cryosurgery treatment" before the Annual Meeting of the British Association of Dermatology, held in Oxford in 1980.

At Pembroke College I visited and attended some dinners and meetings convened for its members, where I had the pleasure to meet nationals of different countries and professions and exchange ideas and opinions on a broad range of culturally enriching topics.

I had the pleasure of meeting Sir Geoffrey Arthur, College Master and Mr. Nicolas Mann, Dean of Graduate Students. They were very kind to welcome me as a member and they guided my steps during my first months in Oxford.

In summary, the experience lived those two years was extremely gratifying and valuable, not just from the academic perspective, but in terms of my personal growth and my own life.

All of us who had the opportunity to study abroad at such prestigious and top quality institutions such as Oxford University, to become the best professionals and honest, self-respecting citizens, have the moral obligation to promote and support these study programs for scientific and humanistic development.

\section{“Dr. José Gregorio Hernández” scholarship}

I graduated at the Universidad Central de Venezuela, in 1976, then I spent a couple of years in Mérida, a small city in the country, following the Internship at the University Hospital, prior to attend the post-graduate program in Orthopaedic Surgery, at the Hospital Vargas, in Caracas.

By the end of the program, I realized that due to the pathology which came to the hospital, mainly injured patients suffering accidents, I had gained a good training in emergencies, dealing with acute lesions, like fractures, dislocations, wounds management, etc., but I needed to complete my training in chronic diseases affecting the musculoskeletal system, like congenital entities, long term joint diseases, pediatric orthopaedics, neoplastic conditions, etc. Therefore I had to do something about that.

I learnt about "Dr. José Gregorio Hernández" scholarship, and I must say that I am very grateful to the Academy, for having selected me at that time for this privilege, I enjoyed for one year, which was extended for a second one, to complete the program. It is fair to recognize the "Dr. José Gregorio Hernández" Foundation, which sponsored the scholarship, and to Pembroke College, which is the responsible for the 
fellows during their stay in Oxford, being so receptive to my person, and concerned with my wellbeing, mainly its Master, sir Geoffrey Arthur, the dean for graduates, Mr. Ken Mayhew, and specially Professor Keith Sykes, head of the Department of Anesthesia, who was assigned as my counselor and supervisor.

The Department of Orthopaedic Surgery of the University of Oxford, was located at the facilities of the Nuffield Orthopaedic Center, in Headington, whose chair was held at that time by Professor Robert Duthie, it was 1981. It was an orthopaedic referral center, where patients, coming from the National Health System corresponding area, suffering from any musculoskeletal disorder, were received to be assisted. It was a very pleasant kind of rather flat building, with several units, the outpatient area, the infirmary, with quite a large garden, with very much green. I remember specially the D block, which was the doctors' area, a very nice two store house, with a very comfortable living room, where the journal club discussions were held. Additionally there were three or four very nice rooms upstairs, where I spent the first few days while I looked for a definitive accommodation. It is impossible to forget Mrs. Hayes, who looked after the place, keeping it clean and tidy, and cooked the lunch for us; she was such a nice person, she was like our grandma.

It is difficult not to appreciate the invaluable discussions during the Grand Rounds with the Professor and the specialists, which had to be rather speedy, but very teaching for all of us. Every week, I believe it was on Thursdays, a special meeting was held in the auditorium for the discussion of a special case, or pathology. Once a month, on Saturdays, we had an special guest, generally coming from abroad, to give a lecture about the area of his expertise, so we had the privilege of listening talks given by well recognized authorities in our field. On Saturdays as well, we had the seminars, I still remember dissecting a foot to give the seminar about this anatomical area.

Orthopaedic surgery covers a very broad area of the body, and a good variety of pathologies, that is why the specialists devoted themselves to different areas, developing a good experience in his own field, that is why the Department worked in different Clinics, such as Pediatrics, Foot, Knee, Hip, Scoliosis, Hand, etc. led by a specialist. Among them I'd like to mention Mr. John Goodfellow, who together with an Engineer, John Connors, developed a model of knee prosthesis, the "Oxford Knee", which still nowadays, more than thirty years later, is successful; Mr. Michael Benson, pediatric orthopedist, who some years later became president of the British Orthopaedic Association. Additionally, at the Center we had a workshop in external prosthesis, with people devoted to rehabilitation, which represented a necessary complement for the treatment of patients suffering from these kinds of pathologies.

During my training in Oxford I was involved in the clinical practice following a rotating program joining the different Clinics, with the specialist in that specific area, both in the outpatient clinic and in surgery, allowing me to concentrate my mind in each area at a time. Additionally, I was involved in few clinical researches, such as Clinical Revision on Arthrogriposis, Evaluation of the results of Total Hip Replacements, Scoliosis and Costoplasty; which represented a very interesting opportunity to learn about how to develop a clinical research. During my rotation in the Scoliosis Clinic, I developed a "Scoliosis Chart", which eventually was very useful for the evaluation of the patients suffering from this condition.

Being in England, I took the chance of visiting sir John Charnley, at the "Hip Center", in Wrigthington, near Wigan, Lancashire, who developed a new concept for total hip prosthesis, proposing the "low friction arthroplasty", which changed the history of this prosthesis towards a reliable success. I learnt a new surgical technique called "arthroscopy", in a course given in Oswestry, Shropshire, by Mr. David Dandy, from Cambridge, who had been trained by Robert Jackson, in Canada, who was disciple of Professor Masaki Watanabe, considered the father of modern arthroscopy, from Japan.

One of the most important things I brought back from Oxford, was a little blue notebook, filled with plenty of telephone numbers and addresses of all the people I met during my stay. There is no doubt that the University of Oxford is one of the most recognized centers for the quest of knowledge, so it explains why one can find people coming from all over the world, in an effort to improve their preparation for a better practice of the profession. It is very satisfactory to look into my little blue notebook, and find the names of so many people one remembers as nice memories. At the hospital I had fellows coming from every continent, with so many different nationalities, with a variety of cultural backgrounds, allowing a very interesting interchange, which definitely enriched the experience of being there.

I remember, at that time we founded what we called the "Fellows' Club", with the idea of joining out for dinner once a month, inviting a special guest, in such a way we had the chance of sharing together in a different atmosphere out of the hospital, in order to increase friendship among ourselves.

Because I finished my postgraduate training in that Department, of that University, not for my own merits, I was invited to incorporate as an "Overseas Fellow" to the British Orthopaedic Association, which I feel proud to belong to.

All the people trained at the Nuffield Orthopaedic Center, are eligible to belong to the "GirdlestoneOrthopaedic Society", named after the first Professor who held the Chair, which is a kind of brotherhood, with a common concern about the progress of the specialty, organizing meetings every year, alternating Oxford with any other place in the world. It is very interesting because it helps the members to keep in touch, sharing their professional experiences, and no academic interests and activities.

I can't avoid sharing the pleasure of enjoying the opera when the Glyndebourne Opera Tour visited Oxford, performing Fidelio, the only opera by Beethoven, or Don Giovanni, by Mozart, which meant wearing a bow tie, and buying a cigar, for afterwards, just for my own pleasure. On the other hand, we cannot ignore, how near Stratford upon Avon, the Shakespeare's birthplace, is from Oxford, allowing me to attend the performance of many of his works, at the same place where the author saw the light for the first time. What about coming to London to enjoy Richard Harris as King Arthur, and Julie Andrews, as Queen Guinevere, performing Camelot ??!! Somehow different, but no less enjoyable, punting was a delightful activity, absolutely typical and unique, in Oxford. I couldn't miss the most traditional contest for British universities, which was the boat race Oxford vs. Cambridge on the Thames' waters; I still keep the "dark blue" badge.

I wanted to refer to all these different aspects, because I believe it is very difficult to do that much, and to get so much, in such a short period of time, and it was possible only because one was at the right place at the right time, and it happened thanks to the scholarship given by the "Dr. José Gregorio Hernández" Foundation, conferred by the Academy of Medicine of Venezuela, which I had the privilege to enjoy.

This opportunity allowed me to realize that the world was round, 
even though at that time people didn't speak jet, about a "global world", I appreciated what I had learnt at home before going there, and finding extremely interesting watching how people coming from all around, with so many different cultural backgrounds, races, languages, life styles etc. could share for a reciprocal benefit and personal enrichment.

I must say that going abroad, to follow a post-graduate training program in such a well-recognized University, like the University of Oxford, meant a priceless blessing for the rest of my life.

There are no words to say thanks to these Institutions, for what it meant, to have had this opportunity to improve both the professional and personal preparation, to face the world and life.

Pedro Ignacio Carvallo, MD

August 2015

\section{Experience of Dr. Leonardo Lustgarten}

The National Academy of Medicine of Venezuela and Pembroke College in Oxford have a longstanding academic relationship established through an educational scholarship named "Jose Gregorio Hernandez". This link was created with funds destined for educational purposes and has enabled Venezuelan professionals of different backgrounds to enhance their knowledge and experience with the highest level of education in a world class University such as Oxford University.

Upon finishing my neurosurgical training in Caracas, Venezuela in December 15, 1995, I was selected for the "Jose Gregorio Hernandez" scholarship. I became a Neurosurgical Specialist Registrar at the Neurosurgical Department, at the Radcliffe Infirmary, Oxford. This was legally possible under the "double sponsorship scheme", the Overseas Doctors Training Scheme of the Royal College of Surgeons of England and approved by the General Medical Council. I achieved further training in Neurosurgery (1995-1997) under the direct supervision and sponsorship of the legendary MrCristopher BT Adams and Mr Peter J Teddy, the latter being the lead consultant of the Department at the time.

The Neurosurgical Department at the Radcliffe Infirmary is one of the oldest and most reputable units in the UK and the world. It is extremely busy being the only unit in the Oxford area (Oxfordshire) dealing with Neurosurgical problems and covering 16 regional hospitals and a population of roughly 4,5 million people. It is formed by the Lead Consultant and 5 other consultants, 5 Neurosurgical Specialist Registrars, and 5 SHO's (Senior House Officers). There are two wards with 36 beds and 6 Neuro ITU beds. Two simultaneous operating theaters are scheduled to run all day, every day, performing approximately 2500-2800 surgeries per year. (As a reference, there is a beautiful historical review of the Department in the published article, Neurosurgery at the Radcliffe Infirmary, Oxford: A History. Aziz TH, Adams CBT. Neurosurgery 1995, 37:3;505-510).

As a Specialist Registrar in Neurosurgery, meaning "neurosurgeon in training" (and even though I was a fully trained neurosurgeon), I was required to fulfill a number of surgical operations, both simple and complex. So I performed, as a main surgeon, an impressive amount of surgeries in the different areas of the field, both, in the elective and the emergency lists, dramatically expanding my previous surgical experience. I also achieved experience with areas of the field I had never been exposed to, particularly stereotactic and functional surgery.

The on-call rota was 1:5, meaning being "on call" every fifth day and covering Oxfordshire (as mentioned, a population of 4,5 million) all by myself. Given the way the British NHS system was organized, neurosurgical emergencies from our 16 regional hospitals were all referred directly to us, operated upon immediately and without delay and after a very brief period of time, sent back for convalescence at their local hospitals.

The Radcliffe Infirmary is a very peculiar hospital in that it is rather small, only held a few specialties (neurosurgery, ENT, plastic surgery and ophthalmology), and did not have a physical emergency area and therefore our surgical emergencies were referred through the telephone and via a "state of the art" image-link system in which all scans were sent via this net (telemedicine). Something extraordinary in the 1990's. I found this to be a most efficient way of dealing with neurosurgical patients (emergencies) as we provided for the quickest and best neurosurgical procedures when needed and discharged the patients when their recoveries could be carried out at their local hospitals. Being such a busy unit, this allowed us to almost always have available beds for our daily complex surgeries at our most critical areas (neuro ITU). The severe trauma shock patients were referred to the John Radcliffe Hospital in Headington, Oxford ("10 minutes across the road") and we would operate in their surgical suites on those particular cases.

As part of my training I also attended the outpatient clinic regularly, as well as the different weekly academic activities such as Grand Rounds with our related departments: Neuroradiology, Neuropathology, Neuro-oncology and Neurology.

I also became involved in clinical research, writing and publishing several clinical articles and chapters for neurosurgical journals and textbooks. Teaching was also an important aspect of the Department, and I lectured the medical students and neurosurgical nurses on many occasions. My experience related to the "Jose Gregorio Hernandez" scholarship was not only limited to the hospital but also included activities as Postgraduate fellow of Pembroke College.

This was another fascinating aspect. I often attended dinners (a gown and trencher was obligatory) at the college at their "High table", a place only destined for postgraduate members and special guests. This is part of a legendary tradition at all colleges in Oxford. It is a symbolic way of demonstrating students' educational hierarchy by having the undergraduate students eat in the normal benches of the dining hall and the "University authorities" eat sitting at a "higher level", thus the name High table. It was placed on the stage in one end of the hall. High table was limited to only 12-14 guests depending on the College and almost invariably included the most prominent scientists, writers, philosophers, theologists, etc, in the world. Most of them held several high educational degrees (MSc, $\mathrm{PhD}$, etc) had written several books, were Nobel price awardees or nominees, and were absolute authorities in their respective fields. Knowledge and wisdom was not only inspiring but contagious in that atmosphere.

Just to illustrate this point with an example, my first encounter in Pembroke College was when interviewed by non else than Sir Roger Bannister (Master of Pembroke College at the time). He is considered one of the most famous neurologists of the past century (author of hundreds of publications and a classical textbook called: Brains Clinical Neurology") and Olympic gold medal winner by being the first athlete to run a mile in less than 4 minutes. I had the unbelievable privilege and honor to drink tea and have a long conversation with him which was most rewarding.

The years spent in the UK thanks to the National Academy of Venezuela and supported by the funds of the Jose Gregorio Hernandez 
scholarship were a once in a lifetime opportunity and I was blessed to have been selected for it.

My previous neurosurgical background was definitely an advantage as I not only mastered my neurosurgical skills but added new condiments from the best neurosurgeons of the world, as well as learning a different philosophical approach to the specialty. As a consequence, I grew and matured as a neurosurgeon and needless to say, as a person, making me a better physician able to care for my patients. I was taught to think with proper clinical judgement and to make always the best possible and honest decisions on behalf of the patients. I was trained with new skills and technology to perform complex and sophisticated surgical procedures in the brain. I learnt when and how to operate, but most importantly, I learnt when not to operate and how to communicate with patients, something never written in textbooks $i$ !

From an academic point of view, it was the most enriching experience any academician could dream of having. It was an atmosphere always being surrounded by wisdom and humility. Interacting at that level of knowledge was inspiring and challenging as it was a constant source for improvement. It allowed me to broaden all sorts of horizons and analyze problems and situations from a different perspective thus probably making better decisions.

Judging by the effect it had on my professional (and personal) life, I consider myself blessed with this unique opportunity and eternally grateful to the National Academy of Medicine of Venezuela and the Jose Gregorio Hernandez foundation for selecting me. No words can possibly describe the true meaning and impact of those years.

I strongly believe that educational grants and foundations such as these, which favor academic enhancement, should be promoted and supported by governments and institutions with a true commitment to education and learning, allowing many professionals of different backgrounds with adequate qualifications to benefit from it.
As time has gone by the true value of these educational schemes at institutions of scientific excellence such as Oxford and Cambridge has emphasized the relevance of this idea promoted in Venezuela: the possibility of providing the means and ways to contribute to the best training of able young physicians with a stable scheme despite the foreseeable economic fluctuations with a plan that was successfully implemented. Amidst a pressing economic crisis that currently limits or fully prevents young physicians from materializing their dream of "pursuing their specialization abroad", these fellowship programs not only give them the possibility to study abroad, but to access those famed universities.

It was extremely difficult to envisage then the troublesome future awaiting us around the corner. This private educational scheme, stable and compliant with rigorous economic criteria, began and in a way was competing against a generous scholarship program launched almost simultaneously by the Venezuelan government. So it was tempting to be drawn towards more favorable conditions that in the end proved to be fleeting and dependent on the ups and downs of a national economy almost exclusively supported by oil revenues. Now it is easy to recognize the wisdom of the private scheme, designed to be a permanent way to train the new generation of physicians of Venezuela.

What is really special and may be unique about this system is the "strategic alliance" between the National Academy of Medicine of Venezuela and Pembroke College, whereby the Academy can select a Venezuelan physician to pursue graduate studies at Oxford University. An extremely valuable opportunity to enrich our healthcare human resources.

Our eternal gratitude to the people and the institutions that with a very accurate insight about the future, designed this system that grants a priceless opportunity to the present and future generations of Venezuelan physicians.

Copyright: (C)2015 Kerdel-Vegas F. This is an open-access article distributed under the terms of the Creative Commons Attribution License, which permits unrestricted use, distribution, and reproduction in any medium, provided the original author and source are credited. 